\title{
Rheumatic fever - new diagnostic criteria
}

\author{
Izabela Szczygielska ${ }^{1}$, Elżbieta Hernik ${ }^{1}$, Beata Kołodziejczyk ${ }^{1}$, Agnieszka Gazda ${ }^{1}$, Maria Maślińska², \\ Piotr Gietka ${ }^{1}$ \\ ${ }^{1}$ Clinic of Developmental Age Rheumatology, National Institute of Geriatrics, Rheumatology and Rehabilitation, Warsaw, Poland \\ ${ }^{2}$ Early Arthritis Clinic, National Institute of Geriatrics, Rheumatology and Rehabilitation, Warsaw, Poland
}

\begin{abstract}
Rheumatic fever (RF) is an autoimmune disease associated with group A $\beta$-hemolytic streptococcal infection, in the course of which the patient develops carditis, arthritis, chorea, subcutaneous nodules and erythema marginatum.

Rheumatic fever diagnosis is based on the Jones criteria, developed in 1944, then revised twice by the American Heart Association (AHA), in 1992 and recently in 2015.

The last revision of the Jones criteria consists mainly in the supplementation of the major criteria with echocardiographic examination, the introduction of a concept of subclinical carditis and the isolation of low, medium and high risk populations among the patients.

AHA recommends that all the patients with suspected RF undergo Doppler echocardiographic examination after the Jones criteria have been verified, even if no clinical signs of carditis are present.

Key words: rheumatic fever, Jones criteria, echocardiography.
\end{abstract}

\section{Introduction}

Rheumatic fever (RF) is an autoimmune, multiorgan inflammatory disease that occurs as a result of group A $\beta$-hemolytic streptococcal infection in genetically susceptible individuals [1].

The patients develop carditis (50-78\%), arthritis (35$88 \%)$, chorea (2-19\%), erythema marginatum (<6\%) and subcutaneous nodules $(<1-13 \%)[2]$.

Acquired heart defects can be a consequence of RF. Estimates show that approximately $60 \%$ of RF patients in endemic countries develop chronic rheumatic heart disease, which is a complication of RF [3]. The risk of chronic rheumatic heart disease is 1.6-2 times higher in female patients [2].

The course of the disease is characterized by relapses, where after the first episode more may follow, thus increasing the risk of heart defects. The risk is the higher the younger the patient is.

Primary prevention of rheumatic fever consists in the proper treatment of streptococcal pharyngitis, and secondary prevention in a long-term administration of penicillin-based drugs.

\section{Epidemiology}

Rheumatic fever is a disease that occurs in every latitude, although its epidemiology is highly diverse. Currently, the annual incidence varies from $<0.5 / 100000$ in highly developed countries to $>100 / 100000$ in poor countries [4].

It is estimated that there are approximately 500000 new RF cases and about 230000 deaths caused by the disease annually on the global scale [5].

Acute RF and its complication in the form of chronic rheumatic heart disease (RHD) remains an enormous health problem in poor countries, while only isolated cases of RF are observed in the countries of Western Europe and North America [4].

This is confirmed by the experience of our Clinic. In the years 2005-2015, nine children were admitted to the Clinic of Developmental Age Rheumatology with a confirmed RF diagnosis. Since 2015, we have not recognized RF in any child.

This decrease in morbidity should be attributed to the improvement in economic conditions, hygiene, a better access to medical care and antibiotic therapy $[1,4]$.

Address for correspondence:

Izabela Szczygielska, Clinic of Developmental Age Rheumatology, National Institute of Geriatrics, Rheumatology and Rehabilitation,

Spartanska 1, 02-637 Warsaw, Poland, e-mail: iza.szczygielska@op.pl

Submitted: 28.12.2017; Accepted: 26.02.2018 
Children aged 6-15 years develop the disease most often, at the same incidence rates among boys and girls. Rheumatic fever symptoms occur 2-3 weeks after streptococcal pharyngitis, never after streptococcal dermatitis. In temperate climates, the highest incidence of RF is observed in the winter and in early spring $[1,6]$.

\section{Rheumatic fever diagnostic criteria}

Rheumatic fever was described for the first time in 1898 in London by William Cheadle [1]. Its symptoms are carditis, subcutaneous nodules, erythema marginatum and polyarthritis.

In 1904, Aschoff described typical histopathological lesions in rheumatic heart disease [3]. The first RF diagnostic criteria were developed in 1944 by Jones, then they were modified by AHA in 1992 (Table I) [7].

They include the major criteria that make up the main clinical presentation of the disease and the minor criteria that comprise the clinical presentation and laboratory tests.

For 23 years, RF diagnosis was based on these criteria.

The diagnosis of a first RF episode required a confirmation of 2 major criteria or 1 major and 2 minor criteria, along with evidence of antecedent group $A \beta$-hemolytic streptococcal infection.

Rheumatic fever can also be diagnosed if the Jones criteria are not met, in the case of isolated chorea or carditis with an insidious onset, long-term course and inconspicuous progression of lesions, after other causes have been excluded.

In the revised 2015 Jones criteria (Table II) [4], a low, medium and high-risk population was identified. A low risk population is one in which cases of acute RF occur in $\leq 2 / 100000$ school-age children or rheumatic heart dis

Table I. Diagnostic criteria for rheumatic fever - modified 1992 Jones criteria [7]

\begin{tabular}{ll}
\hline Major criteria & Minor criteria \\
\hline Carditis & Hyperpyrexia \\
Arthritis & Arthralgia, without other \\
Chorea & signs of inflammation \\
Erythema marginatum & Laboratory indicators of \\
Subcutaneous nodules & acute phase: \\
& ESR, CRP \\
& Prolonged PR interval in ECG
\end{tabular}

And evidence of antecedent streptococcal infection

- Throat swab culture or rapid antigen test

- Elevated/increasing anti-streptococcal antibody titer in serum

$E S R$ - erythrocyte sedimentation rate; $C R P$ - C-reactive protein; $E C G$ - electrocardiography ease is diagnosed in $\leq 1 / 1000$ patients at any age during one year [2, 4, 5].

The modifications introduced in 2015 in the Jones criteria are as follows:

1. In the major criteria:

- Low risk population: clinical and/or subclinical carditis. AHA recommends that all the patients with suspected RF undergo Doppler echocardiographic examination, even if no clinical signs of carditis are present [4]. In doubtful cases it is recommended that echocardiography is repeated.

- Medium and high risk population: also clinical and/ or subclinical carditis and arthritis - monoarthritis or polyarthritis, possibly also with polyarthralgia $[2,4]$.

2. In the minor criteria:

- Low risk population: the parameters of inflammation and the level of fever were defined precisely.

- Medium and high risk population: monoarthralgia, also with defined parameters of inflammation and the level of fever.

The diagnosis of RF in the whole population with evidence of antecedent group A $\beta$-hemolytic streptococcal infection requires a confirmation of two major criteria or one major and two minor criteria - the first episode of the disease.

The diagnosis of subsequent episodes of the disease requires a confirmation of two major criteria or one major and two minor criteria or three minor criteria [2, 4].

Table II. Diagnostic criteria for rheumatic fever - modified 2015 Jones criteria [4]

\begin{tabular}{|c|c|}
\hline \multicolumn{2}{|c|}{ Major criteria } \\
\hline Low risk population & High risk population \\
\hline $\begin{array}{l}\text { Carditis (clinical or subclin- } \\
\text { ical) }\end{array}$ & $\begin{array}{l}\text { Carditis (clinical or subclin- } \\
\text { ical) }\end{array}$ \\
\hline Arthritis - only polyarthritis & Arthritis - monoarthritis or \\
\hline $\begin{array}{l}\text { Chorea } \\
\text { Ervthema marginatum }\end{array}$ & $\begin{array}{l}\text { polyarthritis } \\
\text { Polyarthralgia }\end{array}$ \\
\hline Subcutaneous nodules & Chorea \\
\hline & Erythema marginatum \\
\hline & Subcutaneous nodules \\
\hline \multicolumn{2}{|c|}{ Minor criteria } \\
\hline Low risk population & High risk population \\
\hline Polyarthralgia & Monoarthralgia \\
\hline Hyperpyrexia $\left(\geq 38.5^{\circ} \mathrm{C}\right)$ & Hyperpyrexia $\left(\geq 38.0^{\circ} \mathrm{C}\right)$ \\
\hline $\mathrm{ESR} \geq 60 \mathrm{~mm} / \mathrm{h}$ and/or CRP & $\mathrm{ESR} \geq 30 \mathrm{~mm} / \mathrm{h}$ and/or CRP \\
\hline$\geq 3.0 \mathrm{mg} / \mathrm{dl}$ & $\geq 3.0 \mathrm{mg} / \mathrm{dl}$ \\
\hline Prolonged PR interval (after & Prolonged PR interval (after \\
\hline taking into account the & taking into account the \\
\hline differences related to age; & differences related to age; \\
\hline $\begin{array}{l}\text { If there is no carditis as a } \\
\text { major criterion) }\end{array}$ & $\begin{array}{l}\text { It there is no carditis as a } \\
\text { major criterion) }\end{array}$ \\
\hline
\end{tabular}


Echocardiographic examination is currently the main diagnostic tool used for confirmation, diagnosis and monitoring of valvular lesions in the course of RF, especially in cases of subclinical carditis.

Subclinical carditis is one in which physical examination does not confirm any lesions in auscultation over the heart. Only echocardiography (Doppler) reveals mitral or aortic valve pathology [2].

The echocardiographic criteria developed by AHA in 2012 are as follows $[4,8]$ :

I. Echocardiographic (Doppler) criteria:

- Pathological mitral regurgitation - 4 criteria (all must be met):

1. Visible at least in 2 projections.

2. Regurgitation jet length $\geq 2 \mathrm{~cm}$ at least in 1 projection.

3. Regurgitation peak velocity $>3 \mathrm{~m} / \mathrm{s}$.

4. Regurgitation pansystolic.

- Pathological aortic regurgitation - 4 criteria (all must be met):

1. Visible at least in 2 projections.

2. Regurgitation jet length $\geq 1 \mathrm{~cm}$ at least in 1 projection.

3. Regurgitation peak velocity $>3 \mathrm{~m} / \mathrm{s}$.

4. Regurgitation pandiastolic.

II. Echocardiographic (morphological) criteria:

- In acute mitral valve involvement:

1. Dilatation of mitral annulus.

2. Elongation of chordae tendineae.

3. Rupture of chorda tendinea with acute mitral regurgitation.

4. Prolapse of anterior (less often posterior) leaflet.

5. Nodular lesions on leaflets.

- In chronic mitral valve involvement (invisible in acute involvement):

1. Thickening of leaflets.

2. Thickening of chordae tendinea, with their fusion.

3. Limited mobility of leaflets.

4. Calcifications.

- Lesions in acute and chronic aortic valve involvement:

1. Symmetrical or focal thickening of leaflets.

2. Disturbed leaflet coaptation (leaflet closing during systole).

3. Limited mobility of leaflets.

4. Prolapse of leaflets.

\section{Treatment}

Rheumatic fever treatment has not changed for many years. It covers:

- anti-streptococcal treatment (primary and secondary prevention),

- anti-inflammatory treatment.

\section{Anti-streptococcal treatment}

Primary prevention relies on the proper treatment of streptococcal pharyngitis, that is, prevention of the first RF episode.

The drug of choice is still phenoxymethylpenicillin orally at the following doses: adults and children with a body weight $>40 \mathrm{~kg}-2-3 \mathrm{MIU} /$ day in 2 divided doses every 12 hours for 10 days, children with a body weight $<40 \mathrm{~kg}-100,000$ to 200,000 $\mathrm{lU} / \mathrm{kg} /$ day in 2 divided doses every 12 hours for 10 days.

Benzylpenicillin, administered intramuscularly at a single dose (only in hospital settings), is acceptable, for adults and children with a body weight $>40 \mathrm{~kg}-1.2 \mathrm{MIU}$, children with a body weight $<40 \mathrm{~kg}-600,000 \mathrm{IU}$.

In patients with hypersensitivity to penicillin (except for immediate-type reactions), first-generation cephalosporins (cefadroxil or cefalexin) are used.

Cefadroxil: adults and children with a body weight $>40 \mathrm{~kg}-1 \mathrm{~g}$, children with a body weight $<40 \mathrm{~kg}-30 \mathrm{mg} / \mathrm{kg}$, in a single dose for 10 days.

Cefalexin: adults $500 \mathrm{mg}$ twice per day, children 25$50 \mathrm{mg} / \mathrm{kg} /$ day in 2 doses for 10 days.

Macrolides should only be administered in patients with immediate-type hypersensitivity to beta-lactam antibiotics. The following can be used: erythromycin, clarithromycin and azithromycin.

Erythromycin: adults and children with a body weight $>40 \mathrm{~kg}-0.2-0.4$ g every $6-8$ hours, children with a body weight $<40 \mathrm{~kg}-30-50 \mathrm{mg} / \mathrm{kg} /$ day in 3-4 doses, for 10 days.

Clarithromycin: adults and children with a body weight $>40 \mathrm{~kg}-250-500 \mathrm{mg}$ every 12 hours, children with a body weight $<40 \mathrm{~kg}-15 \mathrm{mg} / \mathrm{kg} /$ day in 2 doses, for 10 days.

Azithromycin: adults and children with a body weight $>40 \mathrm{~kg}-500 \mathrm{mg}$ on the first day, then $250 \mathrm{mg}$ for three consecutive days, children with a body weight $<40 \mathrm{~kg}$ - a single daily dose of $12 \mathrm{mg} / \mathrm{kg} /$ day for 5 days or $20 \mathrm{mg} / \mathrm{kg} /$ day for 3 days [9].

Secondary prevention is the prevention of subsequent rheumatic fever relapses through the chronic anti-streptococcal treatment: phenoxymethylpenicillin or benzathine benzylpenicillin or possibly macrolides.

The duration of secondary prevention must be determined individually, depending on whether the patient has developed carditis and complications in the form of chronic valvular heart disease.

Secondary prevention should be administered from 5 to 10 years from the last RF relapse, or up to 21 years of age (whichever is longer) [2, 10].

In RF cases with carditis leading to chronic valvular heart disease, the prevention should be administered for 10 years or until 40 years of age (whichever is longer) [2]. 
Secondary prevention makes use of benzathine benzylpenicillin, intramuscularly: in adults and children with a body weight $>20 \mathrm{~kg}-1.2 \mathrm{MIU}$, in children with a body weight $<20 \mathrm{~kg}-600,000 \mathrm{IU}$ every 4 weeks [2].

Phenoxymethylpenicillin is administered orally at a dose of $2 \times 250 \mathrm{mg}$ (i.e. $2 \times 400,000 \mathrm{IU}$ ).

\section{Anti-inflammatory treatment}

In the case of heart involvement, glucocorticosteroids (GCs) are used prednisone at a dose of 1-2 mg/ $\mathrm{kg} /$ day for 2-3 weeks, then the dose should be reduced gradually. The total duration of GCs treatment is 6 weeks. During the period of prednisone dose reduction, acetylsalicylic acid should be initiated - at $60 \mathrm{mg} / \mathrm{kg} /$ day [1].

The treatment of chorea is based on sedatives, antiepileptics, in some cases GCs, infusions of immunoglobulins or plasmapheresis.

\section{Discussion}

The diagnosis of RF, especially in developed countries, is a big challenge, mainly for young rheumatologists. Improvement of hygiene conditions, wider access to medical care, targeted treatment bacterial infections with antibiotic resulted in undoubted decrease in the number of cases of RF. However, there are still countries in which more frequent illnesses should be accounted for, as well as in different communities there are also differences resulting from the spread of group A Streptococcus (GAS) variants more or less important for the development of RF, which results in a different incidence of disease $[10,11]$. Lowering the number of cases of RF in recent years in developed countries may also result in a lower experience of doctors and carries the risk of difficulties in making the right diagnosis. Hence it is important to know the criteria for diagnosis.

And inclusion into major criteria, in medium and high risk population, joints pain (polyarthralgia) or inflammation of one joint (monoarthritis), as well as the determination of inflammation and fever rate parameters will allow for early diagnosis and the inclusion of appropriate therapeutic measures. Early diagnosis allows to control the early/acute symptoms of the disease (acute RF) as well as gives the chance to avoid its late sequels like latent rheumatic heart disease (LRHD). In this context, after many years of discussion echocardiography was included into RF criteria. This change seems particularly valuable. Echocardiographic examination is currently of fundamental importance in the diagnosis and monitoring of changes on the valves in the course of RF, especially in cases of subclinical heart inflammation.
Mahfouz et al. [12] used conventional echocardiographic examinations and assessed 2DTDI images found that children with ARF without any evidence of carditis had a significant LV systolic dyssynchrony. Authors suggests that ventricular dyssynchrony as a marker of latent carditis in children with acute rheumatic fever. Beaton et al. [13] examined using echocardiography 227 patients with RF and with latent rheumatic heart disease and assessed risk of poor outcome in this group. The worse prognosis concerned children with moderate to severe intensity of LRHD.

Already in 2004 the World Health Organization (WHO) has recommended echocardiographic screening for RHD in high-prevalence regions as: Australia, Cambodia, Fiji, India, Laos, Mali, Mozambique, New Caledonia, New Zealand, Nicaragua, Pakistan, Samoa, South Africa, Tonga, and Yemen, where screening programs have been introduced [11, 14]. Even before the new criteria were introduced, the World Heart Federation presented criteria for the Diagnosis of Rheumatic Heart Disease which were to facilitate the rapid identification of patients with RHD even without the clear history of acute rheumatic fever but still qualifying for secondary prevention programs [8].

Although elements of the new criteria, which in fact have been known for years, it will also affect groups with high and low risk $(<2 / 100,000$ school children) may be useful in everyday practice, and knowledge of epidemiology as well as about changing risk factors associated with broadly defined environmental factors should help in planning diagnostic route and early diagnosis of RF [15]. The new criteria also allow to make a rheumatic fever relapse not only acute diseases.

\section{Conclusions}

We believe that new criteria will definitely facilitate the diagnosis of rheumatic fever, mainly in doubtful cases and will allow to properly assess the risk associated with the occurrence of LRHD.

The authors declare no conflict of interest.

\section{References}

1. Rutkowska-Sak L, Szczygielska I, Hernik E, et al. Gorączka reumatyczna wczoraj i dziś. Post Nauk Med 2011; suppl. 2: 39-43.

2. Zühlke L, Beaton A, Engel $M$, et al. Group A Streptococcus, acute rheumatic fever and rheumatic heart disease: epidemiology and clinical considerations. Curr Treat Options Cardiovasc Med 2017; 19: 1-23.

3. Undas A. Gorączka reumatyczna. In: Interna Szczeklika. Gajewski P (ed.). Medycyna Praktyczna, Kraków 2015; 355-357. 
4. Gewitz M, Baltimore R, Tani L, et al. Revision of the Jones Criteria for the Diagnosis of Acute Rheumatic Fever in the Era of Doppler Echocardiography: A Scientific Statement From the American Heart Association. Circulation 2015; 131: 18061818.

5. Webb R, Grant C, Harnden A. Acute rheumatic fever. BMJ 2015; 351: h3443.

6. Grzanka K, Kucharz E. Epidemiologia gorączki reumatycznej. Wiad Lek 2003; 7-8: 353-358.

7. Dajani AS, Ayoub E, Bierman FZ. Guidelines for the diagnosis of rheumatic fever. Jones Criteria, 1992 update. Special Writing Group of the Committee on Rheumatic Fever, Endocarditis, and Kawasaki Disease of the Council on Cardiovascular Disease in the Young of the American Heart Association. JAMA 1992; 268: 2069-2073.

8. Reményi B, Wilson N, Steer A, et al. World Heart Federation criteria for echocardiographic diagnosis of rheumatic heart disease-an evidence-based guideline. Nat Rev Cardiol 2012; 7: 297-309.

9. Hryniewicz W, Albrecht P, Radzikowski A. Rekomendacje postępowania w pozaszpitalnych zakażeniach układu oddechowego. Available at: http://www.antybiotyki.edu.pl/pdf/Rekomendacje2016.pdf; 50-56.

10.Esposito S, Bianchini S, Fastiggi M, et al. Geoepidemiological hints about Streptococcus pyogenes strains in relationship with acute rheumatic fever. Autoimmun Rev 2015; 14: 616621.

11. Seckeler MD, Hoke TR. The worldwide epidemiology of acute rheumatic fever and rheumatic heart disease. Clin Epidemiol 2011; 3: 67-84.

12. Mahfouz RA, Alawady WS, Salem AS. Ventricular dyssynchrony as a marker of latent carditis in children with acute rheumatic fever: A tissue Doppler imaging. Echocardiography 2017; 34: 1667-1673.

13. Beaton A, Aliku T, Dewyer A. Latent rheumatic heart disease: identifying the children at highest risk of unfavorable outcome. Circulation 2017; 136: 2233-2244.

14. Carapetis J, Parr J, Cherian T. Standardization of epidemiologic protocols for surveillance of post-streptococcal sequelae: acute rheumatic fever, rheumatic heart disease and acute post-streptococcal glomerulonephritis. Department of Health and Human Services, National Institutes of Health. Available at: https://www.niaidnihgov/topics/strepThroat/Documents/ groupasequelaepdf.

15. de Faria Pereira BA, Rodrigues Belo A, da Silva NA. Febre reumática: atualização dos critérios de Jones à luz da revisão da American Heart Association - 2015. Revista Brasileira de Reumatologia 2017; 57: 364-368. 